circles of the corona are purple alike where they abut on the junction, and what is the order of colours in the semicircle on receding 'from the junction. A record as to which is which of the two halves of the biquartz should be carefully preserved.

Should secondary atmospheric polarisation be so strong as to throw doubt on the results (which may be judged of by noticing the light on the dark moon), it would be well to rotate the analyser till the two halves seen on the dark moon are purple alike, and then alter the pointing of the telescope, and repeat Prazmouski's observation.

It will be observed that the same general principles apply to the elimination of atmospheric polarisation, whether the polariscope employed be a Savart's polariscope, a polariscope with quartz wedges, or a biquartz polariscope.

C. This is of little intrinsic interest, its chief use being to clear up possible doubts as to the results obtained by the observers of $A$ and B. Should there be an observer not otherwise employed, he might be deputed to observe the direction of the Savart's bands on disappearance, both on the dark moon and the surrounding sky, and whether this direction changes during totality. Also it should be specified in which pair of opposite quadrants they were black-centred and in which white-centred. Should this be found impossible or uncertain (the instrument being unprovided with the adjunct mentioned above), the Savart might be used as a simple Nicol by turning it end for end, so that the quartz plates are next the eye; and with this the plane of polarisation might. be roughly determined by means of the azimuth of the principal plane of the Nicol when the light most nearly disappears.

Should registration of the azimuth be attempted, the Savart wonld be fixed so as not to be reversible. In that case the observer might be provided with a double-image prism and diaphragm-tube for separate use in case of need.

Stoppage of stray light in a telescope designed for polarisation

The want of this appears to have occasioned some difficulty at the last eclipse.

The simplest way is by a stop, with a hole just large enough to contain the image of the object-glass. Such exists in the erecting eye-piece, where an image of the object-glass is formed in the body of the eye-piece. It exists too, in a Gregorian or Cassegrainian telescope, where the stoppage is imperative. But in an ordinary refracting telescope, with an inverting eye-piece, the eye-hole (from certain motives of convenience) is larger than in front of $(i . e$. nearer the object-glass than) the bright circle, or image of the object-glass ; and unless the tube is sufficiently provided with stops, when a faint object near a bright one is looked at, light from the bright, reflected from the inside of the tube, is liable to enter the field of view. Large instruments are provided with stops; but $I$ fancy smaller instruments are sometimes tumed out without them. This should be looked to.

The observer may test the correctness of stopping by taking out the eye-piece, inserting a paper disc with a central hole of the size of the field-glass, turning the instrument nearly but not quite to a bright object, as well as to points more distant from the bright object, and noticing whether the side of the tube, even when viewed in a direction grazing the edge of the hole, is properly dark, so that only the edges of the stops are seen." On the other hand, the stops should not obstruct a clear view of the object-glass as seen through the hole representing the fieldglass, or they will render the outer portions of the object-glass useless.

\section{General Renarks}

I consider the observation recommended by Mr. Ranyard (see NATURE, Aug. 24, I87i), very important, IF, after what Prazmouski and Ranyard have done, the point be still deemed doubtful Prazmouski's observation seems to have been beautifully devised and executed, but carelessly described. It is only by conjecture that I can make sense and harmony with what is known, out of his observations as cescribed by himself. But I think that Mr. Ranyard has at least shown that our conjectural interpretation of Prazmouski's observation is the right one; and if so, the point seems settled.

It is for this reason that, in lieu of No. 3 , first half, I proposed something new. What becomes of the magnesium, \&c., which the spectroscope reveals low down in the gigantic puffs which the sun emits? 'T he hydrogen must surely carry the masnesium, $\& c$., with it to the higher regions, though the magriesium, \&c., would soon be condensed, and so would not be detected by the spectroscope. These substances would exist in the form of an

* If reflection occurs from the part of the tulje so near the eye as not to appear zuithin the field, it will not signify much. exceedingly fine haze or dust. I use the two words, "haze" to denote a filmy cloud of molten "dust" of solid matter. This haze or dust is capable of detection, and, according to my interpretation, has been detected, by polarisation; and it is interesting to know how low down it can be detected. Mr. Stoney's speculations as to layers are utterly inapplicable here, as they imply a state of tranquillity quite unlike what we now know to exist, at any rate in connexion with the puffs.

I don't know why, in the second half of No. 3, Mr. Ranyard prescribes placing the line of junction across a sector or rift, if by that he means turning the eye-piece carrying the quartz plates so that the line is perpendicular with the corona to the sector. It would be more likely to yield results if it cut it obliquely, as represented for the corona in Fig. 2. But probably he onIy means pointing the telescope so that the junction cuts the rift. If the observer notices contrasting colours, he may then proceed to determine the plane of polarisation.

G. G. S.

\section{SCIENTIFIC SERTALS}

THe Fournal of the Quekett Microscopical Chub. No. 16. Oc. tober 1871. "Microscopic Work and Conjectural Science," being the address of the President (Lionel S. Beale, M.B., F.R.S.), for the year I871. This address is chiefly occupied in combating the method, presumed to have been adopted, of depreciating one kind of scientific investigation in order to elevate another, and attacks without ceremony those who would elevate physical science to the disparagement of microscopical observation...." On the Examination of the Surface Markings of Diatoms by the Oxy-calcium Light," by N. E. Green. The writer of this paper details his examination of such diatoms as Isthmia, Biddulphia, Triceratium, Pleurosigma, \&c., as opaque objects by high powers, as one-sixth Ross and one-twelfth Gundlach, through the agency of the oxy-calcium light. The conclusion at which he has arrived is, that the markings on all the above, except Pleurosigma, resemble "craters," the surface "being studded with rows of small shallow craters, the sharp edges of which projected slightly above, while the centres seemed to be below the surface." In Pleurosigma a different structure of the surface was observed. "The lime light brought out most distinctly the bead-like character of its markings; they stood out in bold relief like rows of Indian corn," - The Inaugural Address of the South London Microscopical and Natural History Club, by R. Braithwaite, M.D., F.L.S., is principally devoted to suggestions on the vast field for observation at the disposal of the microscopist. - "On Nucleated Sporidia," by M. C. Cooke, M.A. After describing the general structure which prevails in the genus Peziza of Ascomycetous Fungi, the writer details his method of nounting sections for the microscope in pure glycerine. The nucleated sporidia, so prevalent in this genus, are affirmed to be so affected by this method that in a short time all traces of the nuclei are lost, and the object of the paper is to indicate the doubtful value of nucleated sporidia in specific characters. The true nature of such nuclei and their uses are said to be obscure.

IN the Revue Scientifique, Nos. 13-I8, are many valuable articles. Further reports are given of the proceedings of the Edinburgh meeting of the British Association, and a translation of Prof. T. Sterry Hunt's address to the Indianopolis meering of the American Association. We have also a memoir of M. Lartet by M. G. de Mortillet; Helmholtz's paper on the rapidity of propagation of electro-dynamical actions; report of M. Chanveau's lectures on the physiology of virulent maladies; a lecture by $M$. Claude Bernard on the method and principle of physiology; a translation of P. Secchi's paper on the solar protuberances from the Atti dell' Academia ponitificia de nuovi Lincei; a biographical sketch of Haidinger by M. Fouqué; reports of the proceedings of the various scientific institutions in France and Belgium; and translations of lectures delivered at the Royal Institution, University of Edinburgh, \&c., by Prof. Tyndall, Dr. Carpenter, Dr. Laycock, and others.

\section{SOCIETIES AND ACADEMIES \\ PARIS}

Academy of Sciences, October 23.-The greater part of the communications read at this meeting were devoted to chemical subjects. Of mathematical papers only one was presentednamely, a continuation of $\mathrm{M}$. Chasles' memoir on the determina. tion of a series of groups of a certain number of points on a geometrical curve.-A note was read by M. J. Bertrand on the 
mathematical theory of dynamical electricity, and a memoir by M. E. Mathieu on the integration of equations to the partial differences of mathematical physics.-M. du Moncel presented some observations relating to a recent communication by M. Ruhmkorff upen some experiments in magneto-electric induction, in which he claimed to have already ascertained and published facis analogous to those of the German author - M. P. A. Favre read a continuation of his thermic researches upon the electrolysis of the hydracids. - A fifth letter from Father Secchi on the variou; aspects of the protuberances and other remarkable parts of the surface of the sun was read, in which he describes the results of simultaneous observations made by himself at Rome, and by M. Tacchini at Palermo.-M. Secchi also presented a note on a new method of observing the eclipses and passages of Venus, by means of a spectroscopic apparatus modified by having at a distance uf about 20 centimetres in front of the spectroscope, an additional prism having its refringent angle parallel to the fissure.-The chemical papers were as follows :-a theory of simple reactions limited by inverse action, and an application of the same to the transformations of phosphorus, by M. J. Lemoine. -Researches in chemical statics, by M. Stas, containing a discussion of the phenomena which occur in the precipitation of dilute solutions of salts of silver by hydrochloric, hydrobromic, and hydriodic acids, and by chlorides, bromides, and iodides. This paper contains some results of great importance in the analysis of bodies containing silver.-The conclusion of the second part of M. Berthelot's investigation of the ammoniacal salts.-A note on the transformation of glucoses into monatomic and hexatomic alcohols, by M. G. Bouchardat, communicated by M. A. Wurtz. The author acts upon the glucoses by means of an amalgam of sodium. He describes its action upon glucose and sugar of milk. - A note on the hexabromide and hexachloride of silicium, by M. C. Friedel, also presen ed by M. A. Wurtz; and a note on the method of determining the gases evolved by an explosion of nitroglycerine, by M. L. L'Hote, presented by General Morin. From the researches of the last-mentioned author it appears that I gram re of nitroglycerine produces 284 cub. centim. of gas, containing by volume $45^{\circ} 72$ of carbonic acid, 20.36 of binoxide of nitrogen, and 33.92 of nitrogen. - M. Elie de Beaumont called attention to some specimens of native phosphate of lime from Caylux and Cajare, and noticed the importance of these deposits for agricultural purposes. M. Combes also remarked upon this subject.-M. Chapelas presented a note on a remarkable meteor observed during the night of the rgth October.

\section{Philadelphia}

Academy of Natural Sciences, May 9.-The President, Dr. Ruschenberger, in the chair. - Prof. Cope demonstrated some anatomical points of importance in the classification of some of the Siluroids of the Amazon, noticing first those which have no swimning.b'adder, but having the post-temporal bone pierced in a sieve-like manner, forming minute tympana; these he characterised as Otocinclus. Others having huge swim-bladders, gun-boat style of shape. No adipose fin ; the back nalsed. Nolyre plate, indicated as Zathorax. A third, body protected by bony shields above. No adipose fin; the scapular arch dermoössified and lyre-shaped below; indicated as Physopyxis lyra A fourth, shielded all over its sides, with the under lip turned back, genus Corydoras. A fifth, where the under lip is separated, except at the ends, forming loops, named Brochis. In the sixth, where the lips are separated from the beard distally forming chin beards, indicated as Dianema.

May 16.-Dr. Carson, Vice-President, in the chair.--"Remains of Mastodon and Horse in North Carolina."-Prof, Leidy exhibited two photographs, received from Prof. W. C. Kerr, State Geologist of North Carolina, representing some remains of Mastodon americanus found in that State. One of the specimens represented is that of the greater part of the lower jaw of a mature male, retaining both incisor tusks and the last two molar teeth. The latter, with their angular lobes separated by deep angular and nearly unobstructed valleys, are quite characteristic of the species. The incisors are an inch and three-fourths in diameter. The last molar has four transverse pairs of lobes and a well-developed heel. The penultimate molar has three transverse pairs of lobes. The specimen was obtained from gravel overlying the miocene marl near Goldsboro', Lenoir Co., N.C. An isolated last lower molar of the same species, represented in company with the jaw, was obtained in Pit Co.-Prof. Leidy also exhibited a specimen of an upper molar teeth, which Mr. Timothy Conrad had picked up from a pile of miocene marl at
Greenville, Pitt Co., N.C, He suspected, from its size and intricxcy in the folding of the enamel of the islets at the middie of the triturating surface, that the tooth belonged to the post. pliocene Equus complicatus, and was an accidental occupant of the miocene marl. It may, however, belong to a Hipparion of the miocene period, but the imperfection of the specimen at is inner part prevented its positive generic determination.

\section{BOOKS RECEIVED}

EnGisa.-A Manual of the An atomy of Vertebrate1 Animals: Pro? Huxley (Cnurchills). -A Synonymic Catalog te of Diuraal Lepidoptera: W. F. Kirby (Van Voorst). - Description of an Electri : Telegraph: Sir Prof. J. G. Zerf (Hardwicke). - An Elementary Trestise on Statics: J. W. Mulcaster ('laylor and Francis).

Forgign.-(Through Williams and Norgate.)-Verhandlungen des interForEIGN. - (Through Wiliams and Norgate.) - Verhandlungen
nationalen Congress für Alterthumskunde u. Geschichte zu Bonn.

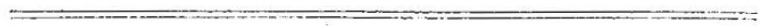

\section{DIARY}

THURSDAY, NOVEMBER 2 .

LINNEAN SOCIETY, at 8.-On the Origin of Insects: Sir John Lubbock, Bart., F.R.S. - Notes on the Natural History of the Flying Fish: Capt, Chimmo - On a Chinese Gall, allied to the European Artichoke Gail: A. Müller, F.L.S.

Chemical Society, at 8.-On Anthraflavic Acid: W. H. Perkin London Instiru'rion, at 7.30-On Michael Faraday; the Story of his Life:
Dr. J. H. Gladstone, F.R.S.

FRIDAY, NOVEMBER 3 .

Geologists' Assoctation, at 8.-On the Old Land Surface; of the Glube Prof. Morris.

$$
\text { MONDAY, NOVEMBER } 6 .
$$

London Institution, at 4.-On Elementary Phỵsiology (II.): Pr.f. Huxley, LL.D., F.R'S.

Anthropological Institute, at 8.-Oa the Order of Succession of the several Stone Implement Periods in England: J. W. Flower, F.G.S.Notes on some Archaic Structures in the Isle of Man: A. L. Lewis.

$$
\text { TUESDAY, NOVEMBER } 7 \text {. }
$$

Society of Biblical Archalogog, at 8.30.-On the Religious Belief of $t^{\prime}$ :e Assyrians: H. Fox Talbot.

HaCkNEY Scientific Association, at 7.30.-Conversazione.

Zootorical Sociery, at $9 .-$ Report on Recent Additions to the Society's Menagerie: The Secretary.-On the Recent Ziphod Whales, with a description of the Skeleton of Berardizes amionxiz: W. H. Flower, F.R.S Taylor Ussher, C.M.Z S.

\section{WEDNESDAY, NOVEMBER 8.} Geological, Society, at 8.-Notes on the Diamond Gravels of the Vaal, in
South Africa: G. W. Stow.-On the Geology of the Diamond Fields of South Africa: Dr. John Shaw.- - Notes on some Fossils from the Devonian Routh Africa: Dr. John Shaw.-Notes on some Fossils from the Devon
Rocks of the Witzenberg Flats, Cape Colony : Prof. T. Rupert Jones. THURSDAY, NOVEMBER 9.

London Mathematical Society, at 8.-On the Partition of an Even Number into two Primes: J. J. Sylvester, F.R.S.

\section{CONTENTS}

PAGE

Ripples and Waves By Prof. Sir William Thomson, F.R S. . . Allbutt on the Ophthalmoscope, By Dr. H. POWER . . . ${ }^{\cdot} 3$ LETTERS TO THE EDITOR:-

An Universal Atmosphere-W. Mattieu Williams, F.C.S. Pendulum Autographs -Geo. S. CARR

Exogenous Structures in Coal-Plants - Prof. W. C WILLIAMson, F.R.S.

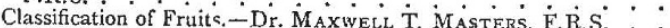

The Berthon Dynamometer-Rev. T. W. WEsB F.RA.S. "

New Form of Cloud .

Spectrum of Blood - $\dot{H}$. C. SokBY, F. $\dot{R} . \dot{S}$.

Earthquake in Burmah. Major CHARLS. . . . . . . . .

A Plane's Aspect.-Dr. T. A. HIRST, F.R.S. ; Dr. C. M. 'IN-

Gleby ; J. K. Laughton - . - . . . . . M. INGeometry at the Universities -Richd. A. Procror, F.R.A.S. :

Debp-Sea Dredging in the Gulf of St. Lawrence. By J. F WHITEAVES

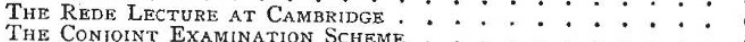

Sir Roderick Murchison. By Prof. Arch. Geikie, $\dot{F} . \dot{R} . \dot{S}$. ( $\dot{W}_{i t} \dot{h}$

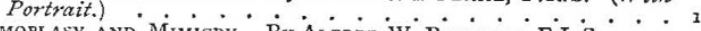
Homoplasy and Mimicry. By Alfred W. Bennett, F.t.S. . : 12 The Grognosy of the Appalachian and the Origin of CrysTAlline Rocks. By Prof. T. Sterky HUNT . . . . . . . . I5

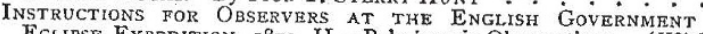
ECLIPSE EXPEDITION, 187r. II.-Polariscopic Observations. (With Diagramis.)

Scirntific Serials

SOCHETHES AND ACADEMIES

BOOKS RECEIVED

DiakY 